MATEC Web of Conferences 46, 02004 (2016)

DOI: $10.1051 /$ matecconf $/ 20164602004$

(C) Owned by the authors, published by EDP Sciences, 2016

\title{
A new fire performance test for cavity wall insulation
}

\author{
Kristin L.T. Jamison ${ }^{1}$ and Daniel A. Boardman ${ }^{2}$ \\ ${ }^{1}$ FM Global, Research Division \\ ${ }^{2}$ FM Approvals, LLC, Materials; 1151 Boston-Providence Turnpike, Norwood, MA 02062, USA
}

\begin{abstract}
Cavity walls containing combustible insulation present an increased risk for fire propagation in a confined, concealed space. Damage to the building resulting from ignition of combustible insulation can be extensive; especially so, in the absence of horizontal and vertical fire-stops. Current codes and standards assess fire performance of exterior wall assemblies subjected to external ignition sources. However, test methods do not address the potential fire hazard resulting from ignition of combustible insulation within the wall cavity. A fire performance test has been developed that evaluates the fire propagation behavior of combustible insulation in a configuration that is representative of the actual installation. The test utilizes a full scale cavity wall assembly and offers fire performance evaluation of insulation of any thickness for either a $51 \mathrm{~mm}$ or $102 \mathrm{~mm}$ wide air space. A propane sand burner was selected as the ignition source; in addition to being reliable and repeatable, its heat output was carefully calibrated to be representative of potential ignition scenarios that may occur within a cavity wall. During the 15 minute fire performance test, the sample is continuously subjected to the propane sand burner exposure fire. An acceptable sample will produce a peak chemical heat release rate less than $100 \mathrm{~kW}$ and a maximum visible flame height less than $1.8 \mathrm{~m}$. This fire performance test method is being incorporated into FM Approvals Standard for Cavity Walls and Rainscreens, Class Number 4411 [1] and is suitable for incorporation into other codes and standards.
\end{abstract}

\section{INTRODUCTION}

Building trends are showing increased use of cavity walls and rain screens on exterior wall construction. Cavity walls typically consist of two walls separated by an air gap. The outer wall is typically of noncombustible construction (e.g., brick or masonry) while the inner wall can be of combustible or noncombustible construction. Cavity walls are primarily used to allow moisture that has penetrated the outer wall to drain down the cavity space where flashing directs the water to weep holes that remove the water from the cavity. These wall assemblies often contain insulation to increase thermal efficiency. Due to the reasons stated above, cavity walls are a desirable construction element. However, there is an increased risk of fire propagation and smoke development when combustible insulation, such as foamed plastics, is used within the cavity wall. In addition, other combustibles such as air or vapor retarders could be present. Such fires would be difficult to locate and extinguish due to both sides being covered, and could result in fire damage, as well as extensive smoke damage.

This is an Open Access article distributed under the terms of the Creative Commons Attribution License 2.0, which permits unrestricted use, distribution, and reproduction in any medium, provided the original work is properly cited. 


\section{MATEC Web of Conferences}

Foamed plastic insulation, such as polystyrene and polyurethane, became commercially available in the 1940's and 1950's [2]. It is a desirable insulation material due to its relatively high insulating value (i.e., R-value), its durability and relative ease of fabrication, it resists corrosion, water, and organisms, and its lightweight construction results in economy of shipping and reduced weight load in buildings [3]. However, many foamed plastics, if ignited, have the potential to create a rapid growing fire with high heat release. There are commercially available insulations that exhibit good fire performance, such as expanded glass, mineral wool and foil faced polyisocyanurate. However, combustible foam plastics such as extruded polystyrene, expanded polystyrene and polyurethane are often used in lieu of these good performers because of their economy and relatively high insulating value. Furthermore, they have not been precluded from use in construction in spite of adverse fire test experience. While current codes and standards assess the fire performance of exterior wall assemblies $[4,5]$ subject to an external ignition source, none to date address the potential for an ignition source inside a cavity wall assembly.

In response to the international energy crisis of the 1970's, the use of foam plastic insulation in building construction increased in an attempt to gain thermal efficiency; codes and standards of the time lacked appropriate guidance and test standards to address the potential fire hazard. The Federal Trade Commission (FTC), in response to a number of large fire losses, conducted an investigation into the manner in which foam insulation fire performance was being described. Based on this investigation, the FTC Consent Cease and Desist Order was issued on November 4, 1974 and instructed the foam plastic industry to stop using terms such as "non-burning", "self-extinguishing" or "non-combustible" when describing foam plastic products. The flammability terminology had been based on results from fire testing per ASTM D1692: Standard Method of Test for Flammability of Plastic Sheeting and Cellular Plastics [6] and ASTM E84: Standard Test Method for Surface Burning Characteristics of Building Materials [7]. Both tests are conducted with the test specimen in the horizontal position. ASTM D1692, which was first issued in 1959, subjected the test specimen to a horizontal Bunsen burner flame for 60 seconds. A successful specimen was labeled as "non-burning" or "self-extinguishing" if it passed the test, meaning that ignition did not occur, or the flame spread rate was low. The ASTM E84 test, introduced in 1941 and known as the Steiner tunnel, subjects a test specimen, which is installed along the top of the horizontal test tunnel, to an open flame ignition source. The rate of horizontal flame propagation is used to provide a relative ranking termed the flame spread index (FSI). Both tests highlighted that some foam plastics have different burning characteristics than conventional materials such as cellulosic materials; they can shrink away from the flame, melt, drip and intumesce to an extent that results of the tests can indicate artificially favorable fire characteristics [7-9].

The FTC determined that there was misuse of small-scale fire test data and issued a requirement that products which referenced a numerical flame spread rating would contain a disclaimer stating "this numerical flame spread rating is not intended to reflect hazards presented by this or any other material under actual fire conditions". The ASTM D1692 standard was withdrawn in 1976; however, ASTM E84 continues to be used today in lieu of its deficiencies for foam plastics. Research continues to show that "favorable" flame spread ratings of foam plastic materials (as determined by ASTM E84) do not guarantee a favorable fire performance in certain fire tests, including room tests and tests of flame spread within wall cavities $[8,10]$. Current codes require that all commercially available foam plastic be tested to ASTM E84 and have a FSI less than 75 and a smoke development index (SDI) less than 450. When installed in a habitable space the foam plastic must be covered by a thermal barrier $[4,5,11]$ unless the insulation has passed NFPA 286: Standard Methods of Fire Tests for Evaluating Contribution of Wall and Ceiling Interior Finish to Room Fire Growth [12]. This method measures flame spread in a room configuration, including fire spread along walls, ceilings, and combinations of both. It is more indicative of real world fire hazards, and is preferred over ASTM E84 and it's equivalent UL 723 [13], but is more expensive [14]. Foam plastics that perform well during ASTM E84 testing have resulted in spectacular failures when tested to NFPA 286. These conflicting results lead to questions concerning the technical validity of using ASTM E84 for some types of foam plastics. 
As a result of the 1974 FTC Consent Order the plastics manufacturers were tasked with conducting research to determine a safe means of using foam plastics. The foam plastic industry paired with Underwriters Laboratories, LLC (UL) and the National Bureau of Standards (now the National Institute of Standards and Technology or NIST) to develop new fire tests for foam insulation [15]. These included material tests (individual components) and assembly tests (a specific combination of building components representative of the actual construction). NFPA 285: Standard Fire Test Method for Evaluation of Fire Propagation Characteristics of Exterior Non-Load-Bearing Wall Assemblies Containing Combustible Components [16] was developed as a result of that research and the test method has been incorporated into international codes such as the International Building Code (IBC) [4] and NFPA 5000: Building Construction and Safety Code [5]. Results of NFPA 285 are based on the specific assembly and changes in a single component may result in substantial changes in the assembly's fire performance. Additionally, a test assembly that successfully passes NFPA 285 provides assurance of good fire performance under fully constructed conditions with careful attention to the assembly integrity. However, rapid and intense fire development may occur if the combustible insulation is exposed to an ignition source via a penetration in the finished assembly or improper fire stopping, or by grinding, welding or cutting during the building construction phase.

Walls that require a fire-resistance rating are tested to NFPA 251: Standard Methods of Tests of Fire Endurance of Building Construction and Materials [17], or an equivalent standard [5, 18, 19], which subjects an assembly to a standard fire exposure and provides an hourly rating for fire-resistance. This method, as with NFPA 285, only indicates the fire performance of a specific assembly under fully constructed conditions whose exterior surface is subjected to a fire exposure. Another test method used to assess the fire performance of exterior walls is NFPA 268: Standard Test Method for Determining Ignitability of Exterior Wall Assemblies Using a Radiant Heat Energy Source [20]. This test method determines the propensity of ignition of exterior wall assemblies from exposure to a radiant heat source in the presence of a pilot flame. It is not intended to evaluate the fire endurance of wall assemblies, nor is it intended to evaluate the effect of fires originating within the building or within the exterior wall assemblies [20].

The 2015 edition of NFPA 5000, which has similar requirements to Chapter 26 of the IBC, specifies that exterior walls of buildings of Type I, II, III or IV construction containing foam plastic shall meet the following requirements: fire resistive rating, if applicable [17-19], contain a thermal barrier [11] covering the foam plastic insulation, the foam plastic must meet NFPA 259: Standard Test Method for Potential Heat of Building Materials [21] and ASTM E84 requirements, and the assembly must meet NFPA 285 and NFPA 268 requirements. There is no one test that can accurately determine the fire performance of a wall assembly under all fire conditions; therefore it is necessary, as is seen in NFPA 5000 , to utilize material tests in conjunction with assembly tests to create a general indication of fire performance. The existing assembly tests do not directly expose the combustible insulation and do not address the potential of a small ignition source within the wall cavity that simulates exposure from hot work or electrical equipment. Additionally, ASTM E84 is the sole material test requirement that assesses flame spread. For these reasons, it was desirable to develop a test method that adequately assesses the fire performance of combustible insulation when installed in its final configuration within a wall cavity.

The purpose of this program was to recommend a test method capable of evaluating the flammability of insulations when installed in non-combustible cavity walls [22]. A full scale cavity wall panel test method was evaluated using sample insulation materials. A sand burner ignition source was developed to ensure the appropriateness of the intensity and duration of the exposure fire. The effect of the air cavity width was also considered as the potential fire severity might increase with increasing air cavity size (up to a certain threshold). Air cavity widths of $51 \mathrm{~mm}$ and $102 \mathrm{~mm}$ were evaluated as the width typically falls within range of these values [23]. 




(a)



(b)

Figure 1. Cavity wall panel test apparatus (a) and close-up view of the sand burner, insulation sample and test apparatus (b).

\section{TEST APPROACH}

Testing was conducted at the FM Global Research Campus in the Fire Technology Building, West Glocester, Rhode Island, USA. Rigid extruded polystyrene and sprayed polyurethane foam insulation were selected for testing. Selection of these insulations allowed for observations to be made of a sample that exhibited poor fire performance (rigid extruded polystyrene) and a sample that exhibited good fire performance (sprayed polyurethane).

Each sample material was installed in a test apparatus that replicated the geometry of a cavity wall and was subjected to a sand burner fire exposure. The test apparatus consisted of two $1.2 \mathrm{~m}$ wide by $2.4 \mathrm{~m}$ high steel frames. A single layer of $13 \mathrm{~mm}$ DensGlas Gold (glass faced gypsum board) or Marinite-I was fastened to each frame with dry-wall screws to simulate non-combustible sheathing or veneer. Each piece of DensGlas or Marinite was backed by a sheet of $13 \mathrm{~mm}$ thick fire retardant (FR) plywood. The test sample was then fastened to one frame. The two frame units were positioned parallel to each other with either a $51 \mathrm{~mm}$ or $102 \mathrm{~mm}$ air gap between the face of the sample and that of the non-combustible panel. Steel sheet metal flashing was installed along the top of the cavity wall to simulate a vertical firestop. Additionally, the bottom of the cavity wall was sealed with sheet metal in order to maintain realistic air flows within the cavity. A slot was placed in the bottom piece of steel sheet metal to accommodate the $305 \mathrm{~mm}$ long by $51 \mathrm{~mm}$ or $102 \mathrm{~mm}$ wide sand burners. The test configuration is shown in Fig. 1 .

A total of eleven $1.2 \mathrm{~m}$ wide by $2.4 \mathrm{~m}$ high samples were tested under a 5-MW calorimeter. Heat release rate (HRR) measurements were taken throughout the tests. All tests were digitally recorded and visual observations of the fire growth, flame height and thermal damage were made.

\subsection{Exposure fire}

It was important to select an exposure fire that was representative of a potential accidental ignition source within a cavity wall (i.e., welding and cutting torches). An oxy-acetylene torch, although it serves as a representative ignition source, is prone to be operator dependent and is not a consistent ignition source. 
Therefore, to provide a steady and repeatable fire exposure and to be consistent with other standards $[12,24-26]$, two propane sand burners were selected for use in this study.

A $51 \mathrm{~mm} \times 305 \mathrm{~mm}$ sand burner was selected for the $51 \mathrm{~mm}$ wide cavity tests and a $102 \mathrm{~mm} \times$ $305 \mathrm{~mm}$ sand burner was selected for the $102 \mathrm{~mm}$ wide cavity tests. To be consistent with current FM Approvals test methods and to incorporate an exposure fire known to be representative of common accidental fires, it was decided that the new sand burners should have the same chemical HRR per unit surface area output as the $60 \mathrm{~kW}$ sand burner used in the FM Approvals Standard 4910 parallel panel test [25]. This $60 \mathrm{~kW}, 305 \mathrm{~mm} \times 610 \mathrm{~mm}$ sand burner has a chemical HRR per unit surface area of $323 \mathrm{~kW} / \mathrm{m}^{2}$. Keeping the same HRR per unit area output resulted in a theoretical $5 \mathrm{~kW}$ exposure from the $51 \mathrm{~mm} \times 305 \mathrm{~mm}$ sand burner and a $10 \mathrm{~kW}$ exposure from the $102 \mathrm{~mm} \times 305 \mathrm{~mm}$ sand burner.

These target HRRs were assessed for appropriateness by comparison to those generated by an oxyacetylene torch. For the purpose of this comparison, use of a torch with a number 4 tip is assumed, which operates at flow rates between 4.7 and $14 \mathrm{~L} / \mathrm{min}$ [27]. The theoretical chemical HRR of the oxyacetylene torch can be determined by considering the following expression which used the ideal gas law:

$$
H R R=\frac{P}{(R / M) T} \dot{V} \Delta H_{\mathrm{c}} .
$$

Where $P$ is the pressure, $T$ is the temperature, $R$ is the universal gas constant $(8.314472 \mathrm{~J} / \mathrm{mol} / \mathrm{K}), M$ is the molar mass of the gas, $\dot{V}$ the volumetric flow rate and $\Delta H_{c}$ is the total heat of combustion of the gas. Assuming complete stoichiometric combustion at standard pressure and temperature conditions (i.e., $P=1 \mathrm{~atm} ; T=298.15 \mathrm{~K})$ in which the working gas is acetylene $\left(\Delta H_{c}=48.27 \mathrm{MJ} / \mathrm{kg}, M=\right.$ $26.04 \mathrm{~g} / \mathrm{mol}$ ), Eq. (1) yields a theoretical chemical HRR of $4.0 \mathrm{~kW}$ and $12.1 \mathrm{~kW}$ for the 4.7 and $14 \mathrm{~L} / \mathrm{min}$ flow rates, respectively. The target chemical HRR outputs from the two sand burners are within the range of the theoretical chemical HRR output from an oxy-acetylene torch.

Prior to conducting fire testing of the samples, the two sand burners were calibrated in order to determine the propane flow rate required to achieve the desired $5 \mathrm{~kW}$ and $10 \mathrm{~kW}$ fire exposures. Equation (1) can be rearranged to calculate the volumetric flow rate that should be provided to a sand burner given a desired HRR. For example, for the $51 \mathrm{~mm} \times 305 \mathrm{~mm}$ sand burner with a target $H R R=5.0 \mathrm{~kW}$, assuming standard conditions (i.e., $P=1 \mathrm{~atm} ; T=298.15 \mathrm{~K}$ ) in which the working gas is propane $\left(\Delta H_{c}=46.35 \mathrm{MJ} / \mathrm{kg}, M=44.0956 \mathrm{~g} / \mathrm{mol}\right)$ one obtains a volumetric flow rate of $3.6 \mathrm{~L} / \mathrm{min}$. Likewise, for the $102 \mathrm{~mm} \times 305 \mathrm{~mm}$ sand burner with a target $H R R=10 \mathrm{~kW}$, one obtains a volumetric flow rate of $7.2 \mathrm{~L} / \mathrm{min}$.

\subsection{Heat flux measurements}

It was important to ensure that the incident heat flux to the sample surface from both burners was reasonable and similar in magnitude. Measurements of the incident heat flux were recorded during the calibration of the sand burners. A heat flux gage $0-100 \mathrm{~kW} / \mathrm{m}^{2}$ was placed along the centerline of a Marinite wall panel (in place of the insulation sample) at heights of $152 \mathrm{~mm}$ and $305 \mathrm{~mm}$ above the sand burner surface. Figure 2 shows the incident heat flux as a function of burner HRR.

The incident heat flux measured $305 \mathrm{~mm}$ above both sand burners at the target HRRs was $20 \mathrm{~kW} / \mathrm{m}^{2}$. However, at these target HRRs, the heat flux measured $152 \mathrm{~mm}$ above the burner was $30 \mathrm{~kW} / \mathrm{m}^{2}$ and $50 \mathrm{~kW} / \mathrm{m}^{2}$ from the from the $51 \mathrm{~mm}$ and $102 \mathrm{~mm}$ wide sand burners, respectively. This would result in significantly less severe thermal shock to the test samples in the $51 \mathrm{~mm}$ wide cavity wall test than in the $102 \mathrm{~mm}$ wide cavity wall test. Since it was desirable to maintain a similar maximum heat flux to the samples in both tests, new target HRRs of $5.8 \mathrm{~kW}$ and $9.5 \mathrm{~kW}$ were selected for the $51 \mathrm{~mm}$ and $102 \mathrm{~mm}$ wide burner, respectively. The corresponding propane volumetric flow rates were $4.2 \mathrm{~L} / \mathrm{min}$ and 


\section{MATEC Web of Conferences}



Figure 2. Incident heat flux to panels resulting from varying chemical heat release rates.

6.8 $\mathrm{L} / \mathrm{min}$, respectively. At these new HRRs, the heat flux to the sample surface $152 \mathrm{~mm}$ above the propane burners was $40 \mathrm{~kW} / \mathrm{m}^{2}$.

\subsection{Cavity wall insulations samples}

Six tests were conducted with rigid extruded polystyrene. For each test, two pieces of rigid extruded polystyrene boards, $0.6 \mathrm{~m}$ wide by $2.4 \mathrm{~m}$ long by $51 \mathrm{~mm}$ thick, were secured to the non-combustible sheathing, with the seam running vertically up the sample, to form the $1.2 \mathrm{~m}$ wide by $2.4 \mathrm{~m}$ high samples as shown in Fig. 3(a).

The remaining five tests were conducted with sprayed polyurethane foam. The polyurethane foam was applied to the $1.2 \mathrm{~m}$ by $2.4 \mathrm{~m}$ non-combustible sheathing at a nominal thickness of $51 \mathrm{~mm}$ as shown in Fig. 3(b). All five sprayed polyurethane samples were of the same size and construction. It is important to note that, unlike the rigid extruded polystyrene with a uniform $51 \mathrm{~mm}$ thickness, the sprayed polyurethane samples had non-uniform cross-sectional thickness due to the spray application technique. While a nominal $51 \mathrm{~mm}$ thickness was maintained, certain areas of the samples were thicker or thinner by up to $25 \mathrm{~mm}$.

\section{TEST PROCEDURE}

Tests were conducted under the FM Global 5-MW fire products collector. The combustion products drawn by the collector are transported to an instrument station where gas species concentrations, temperature and pressure are measured. The gas analysis is capable of providing realtime chemical HRR information based on the total gas mass flow rate and measured concentrations of $\mathrm{CO}$ and $\mathrm{CO}_{2}$.

Samples were constructed with either a $51 \mathrm{~mm}$ or $102 \mathrm{~mm}$ air gap between the exposed surfaces of the parallel panels. In the case of the uneven sprayed polyurethane samples, this gap was measured from the average surface plane of the samples. Depending on the gap between the face of the sample and that of the opposing non-combustible panel, test samples were either subjected to a $51 \mathrm{~mm}$ or a $102 \mathrm{~mm}$ wide sand burner fire exposure. Rigid extruded polystyrene and sprayed polyurethane samples are shown in Fig. 3(c) and 3(d), respectively, for the $102 \mathrm{~mm}$ wide test configuration. A summary of the samples and the test conditions is given in Table 1. 




(a)

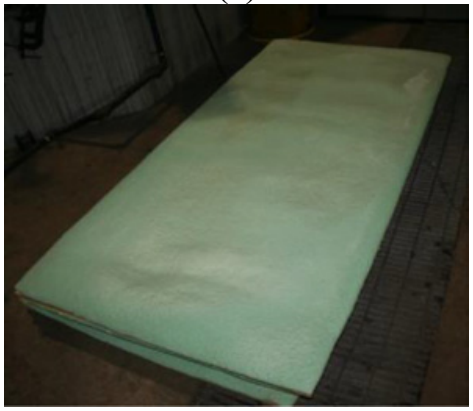

(b)



(c)



(d)

Figure 3. Rigid extruded polystyrene sample (a), sprayed polyurethane sample (b), rigid extruded polystyrene sample with $102 \mathrm{~mm}$ wide cavity (c) and sprayed polyurethane sample with $102 \mathrm{~mm}$ wide cavity (d).

The first six tests were conducted with rigid extruded polystyrene samples. Demonstration tests, conducted in a previous study indicated that poor fire performance could be expected from the rigid extruded polystyrene samples [28]. Tests 1 through 6 were conducted to verify this performance in the proposed test configurations and to establish the repeatability of the tests. The fire exposure period for all six tests was 15 minutes. Tests 1-3 were conducted with a $51 \mathrm{~mm}$ air gap (i.e., $5.8 \mathrm{~kW}$ exposure) and Tests 4-6 were conducted with a $102 \mathrm{~mm}$ air gap (i.e., $9.5 \mathrm{~kW}$ exposure).

Tests 7 through 11 were conducted with the sprayed polyurethane foam samples which were expected to exhibit good fire performance. Tests 7 through 9 were conducted to verify this good performance in comparison to Tests 1 though 6 . The air gap was $51 \mathrm{~mm}$ in Test 7 and $102 \mathrm{~mm}$ in Tests 8 and 9; however, the exposure time was increased to 20 minutes to ensure that the 15 minute exposure period was long enough to adequately distinguish between good and poor performance. Tests 10 and 11 were conducted with a $102 \mathrm{~mm}$ air gap and an increased sand burner heat output in order to ensure that the previous tests were severe enough. The sand burner was adjusted to achieve a $15 \mathrm{~kW}$ heat release rate output with an initial exposure period of 15 minutes in Test 10 and an increased exposure period of 30 minutes in Test 11.

\section{TEST RESULTS AND DISCUSSION}

Results from the cavity wall panel tests are summarized in Table 1 below. The peak chemical heat release rate, maximum visible flame height and the height of the charred area of the samples were recorded. 
Table 1. Summary of cavity wall test parameters and results.

\begin{tabular}{clcccccc}
\hline $\begin{array}{c}\text { Test } \\
\#\end{array}$ & $\begin{array}{c}\text { Insulation } \\
\text { Type }\end{array}$ & $\begin{array}{c}\text { Test } \\
\text { Duration } \\
(\mathrm{min})\end{array}$ & $\begin{array}{c}\text { Cavity } \\
\text { /Sand } \\
\text { Burner } \\
\text { Width } \\
(\mathrm{mm})\end{array}$ & $\begin{array}{c}\text { Sand } \\
\text { Burner } \\
\text { Fire } \\
\text { Exposure } \\
(\mathrm{kW})\end{array}$ & $\begin{array}{c}\text { Peak } \\
\text { Chemical } \\
\text { Heat } \\
\text { Release } \\
\text { Rate }^{\dagger}(\mathrm{kW})\end{array}$ & $\begin{array}{c}\text { Maximum } \\
\text { Flame } \\
\text { Height } \\
(\mathrm{m})\end{array}$ & $\begin{array}{c}\text { Height of } \\
\text { Char } \\
(\mathrm{m})\end{array}$ \\
\hline 1 & & 15 & 51 & 5.8 & 835 & $>2.4$ & 2.4 \\
2 & Rigid & 15 & 51 & 5.8 & 1020 & $>2.4$ & 2.4 \\
3 & extruded & 15 & 51 & 5.8 & 1100 & $>2.4$ & 2.4 \\
5 & polystyrene & 15 & 102 & 9.5 & 1270 & $>2.4$ & 2.4 \\
6 & & 15 & 102 & 9.5 & 1630 & $>2.4$ & 2.4 \\
\hline 7 & & 15 & 9.5 & 1460 & $>2.4$ & 2.4 \\
8 & Sprayed & 20 & 51 & 5.8 & $<100$ & 1.8 & 1.8 \\
9 & polyurethane & 20 & 102 & 9.5 & $<100$ & 1.2 & 1.2 \\
10 & foam & 15 & 102 & 9.5 & $<100$ & 1.1 & 0.9 \\
11 & & 30 & 102 & 15 & $<100$ & 2.3 & 2.1 \\
\hline
\end{tabular}

$\dagger$ The lowest chemical heat release rate which the 5-MW calorimeter is capable of accurately measuring is $100 \mathrm{~kW}$ [29]

\subsection{Rigid extruded polystyrene test results}

Figures 4(a) and 4(b) show representative images of the maximum flame height for Tests 1-3 and 4-6, respectively. The observed flame heights were above the $2.4 \mathrm{~m}$ height of the test panels during all six tests. It is noted that this specific material had a FSI of 5 as measured by the ASTM E84. The observed damage to the samples in Tests 1-3 was also very similar, with charred insulation extending the full length of the samples. The central portion of the insulation samples was entirely consumed during each of the three tests. A picture of the sample from Test 1 is shown in Fig. 4(c) which is representative of the observed damage to all three samples. The damage to the samples in Tests 4-6 was also very similar, with nearly all of the insulation consumed during the test. A picture of the sample from Test 5 is shown in Fig. 4(d) which is representative of the damage observed on all three samples.

In terms of the peak chemical heat release rate, the resulting fires in the $51 \mathrm{~mm}$ wide cavity tests ( 835 to $1,100 \mathrm{~kW}$ ) were less severe than those in the $102 \mathrm{~mm}$ wide cavity tests $(1,270$ to $1,630 \mathrm{~kW})$. The wider cavity space allows for increased air entrainment and more burning of the samples. This increases the wall temperatures. Also, the optical thickness of the flames increases, resulting in higher heat fluxes [30].

\subsection{Sprayed polyurethane foam test results}

As expected, the sprayed polyurethane samples performed better than the rigid extruded polystyrene samples. In terms of peak chemical heat release rate, the fire intensity observed in the rigid extruded polystyrene tests $(835$ to $1,630 \mathrm{~kW}$ ) was much more severe than in the fires from the sprayed polyurethane tests $(<100 \mathrm{~kW})$. Maximum visible flame heights were lower and observed damage and charring did not extend the full length of the test samples. Maximum flame heights achieved in Tests 7 and 9 are shown in Fig. 5(a) and 5(b), respectively, while post test damage and charring are shown in Fig. 5(c) and 5(d). Refer to Table 1 for a summary of results. Test 7, with a $51 \mathrm{~mm}$ wide cavity space, and Tests 8 and 9, with $102 \mathrm{~mm}$ wide cavity spaces, reached maximum flame heights within the first 
$2^{\text {nd }}$ International Seminar for Fire Safety of Facades, Lund (Sweden), 2016



(a)

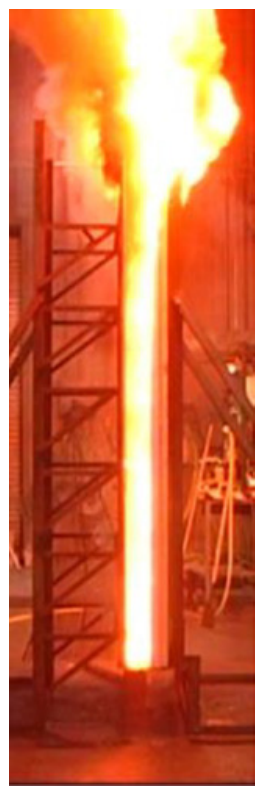

(b)



(c)

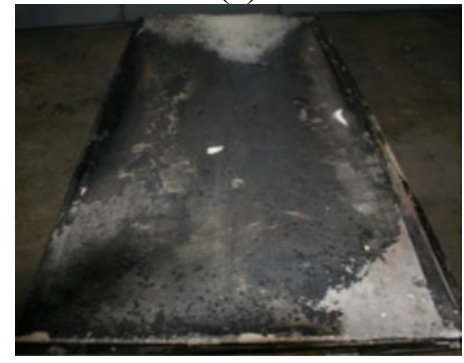

(d)

Figure 4. Observed maximum flame height Test 1 (a) and Test 5 (b), sample damage Test 1 (c) and Test 5 (d).



(a)

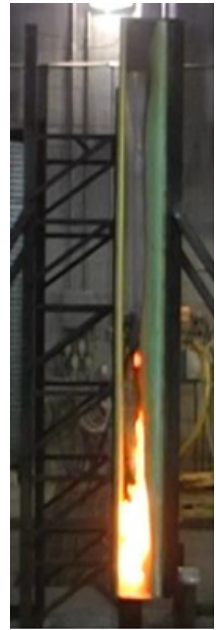

(b)



(c)



(d)

Figure 5. Observed maximum flame height Test 7 (a) and Test 9 (b), sample damage Test 7 (c) and Test 9 (d).

15 minutes of the tests. No additional upward flame spread was observed during the extended exposure period of these tests.

The final two tests (Tests 10 and 11) were conducted with an increased fire exposure of $15 \mathrm{~kW}$. Both tests showed increased flame heights and damage to the samples when compared to Tests 7 through 9. However flame heights and charring still did not reach the full $2.4 \mathrm{~m}$ height of the test panels. The observed maximum sustained flame height in Test 11, with a 30 minute exposure was lower than that 
observed in Test 10 with a 15 minute exposure. This is further evidence that irregularities in the samples, rather than test conditions, contributed to unexpected variations in the flame heights. It is also important to note that the maximum flame height in Test 11 was observed during the initial 15 minutes of the test, further indicating that the 15 minute test duration is sufficient.

\section{CONCLUSIONS}

A test protocol for incorporation of cavity walls into FM Approvals Standard for Cavity Walls and Rainscreens, Class Number 4411 has been presented and validated. Test results indicate that the proposed cavity wall panel test method is appropriate for evaluating the flame propagation characteristics of cavity wall insulation materials. The rigid extruded polystyrene samples supported flame spread beyond the $2.4 \mathrm{~m}$ height of the test apparatus while the sprayed polyurethane samples supported flame spread to less than $1.8 \mathrm{~m}$. Charring or complete consumption of rigid extruded polystyrene samples was visible over the full $2.4 \mathrm{~m}$ length of the samples while charring on sprayed polyurethane samples was limited to a maximum length of $1.8 \mathrm{~m}$. The peak chemical heat release rates measured during the rigid extruded polystyrene tests were 835 to $1,630 \mathrm{~kW}$ while the peak chemical heat release rates measured during the sprayed polyurethane tests were below $100 \mathrm{~kW}$. Tests conducted with sprayed polyurethane samples subjected to an increased exposure fire of $15 \mathrm{~kW}$ did not yield significantly different results, with the sprayed polyurethane still exhibiting good fire performance. The flame height was less than $2.4 \mathrm{~m}$ and charring was less than $2.1 \mathrm{~m}$. Based on these test results, the exposure fires of $5.8 \mathrm{~kW}$ in the $51 \mathrm{~mm}$ wide cavity test and $9.5 \mathrm{~kW}$ in the $102 \mathrm{~mm}$ wide cavity test provide an appropriate thermal insult to the samples in order to make a judgment of acceptable performance. In all tests, maximum visible flame heights were observed before the tests reached 15 minutes. In those tests with a 30 minute exposure, no significant thermal damage to the samples was observed after 15 minutes. These results indicate that the 15 minute exposure period is appropriate for evaluating the performance of cavity wall insulation materials in the cavity wall panel test. Tests were conducted with a $51 \mathrm{~mm}$ wide and a $102 \mathrm{~mm}$ wide cavity between parallel surfaces. The results of six tests conducted with rigid extruded polystyrene, three in each test configuration, indicate that the $102 \mathrm{~mm}$ wide test is more severe than the $51 \mathrm{~mm}$ wide test. Higher flame heights and more intense fires (in terms of chemical heat release rate) were observed in the $102 \mathrm{~mm}$ wide tests. Similar observations and chemical heat release rate measurements were made in each of the three tests conducted under the same conditions, indicating that the test is capable of providing repeatable results.

\section{RECOMMENDATIONS}

The fire performance tests evaluated in this study should be used to quantify the heat release rate and maximum flame height of combustible components (insulation and air/vapor retarders) within a cavity wall construction. Even though the two test configurations, a $51 \mathrm{~mm}$ and a $102 \mathrm{~mm}$ wide cavity test, lead to differences in insulation fire severity that are relatively small, both may be adopted, if the added flexibility from the choice is deemed to be of value. The $51 \mathrm{~mm} \times 305 \mathrm{~mm}$ and $102 \mathrm{~mm} \times 305 \mathrm{~mm}$ propane sand burners are recommended for the $51 \mathrm{~mm}$ wide and $102 \mathrm{~mm}$ wide cavity tests, respectively. The $51 \mathrm{~mm} \times 305 \mathrm{~mm}$ sand burner should be adjusted to a propane flow rate of $4.2 \mathrm{~L} / \mathrm{min}$ to achieve a chemical heat release rate of $5.8 \mathrm{~kW}$. The $102 \mathrm{~mm} \times 305 \mathrm{~mm}$ sand burner should be adjusted to a propane flow rate of $6.8 \mathrm{~L} / \mathrm{min}$ to achieve a chemical heat release rate of $9.5 \mathrm{~kW}$.

A 15 minute test duration for both the $51 \mathrm{~mm}$ wide test and the $102 \mathrm{~mm}$ wide test is recommended. The propane sand burner output should be constant throughout the test duration. Propane to the sand burner should be shut off and the samples should be extinguished at the end of the 15 minute exposure period. Chemical heat release rate and visual flame height should be measured throughout the duration of the test. Based on the results of testing conducted in this study, acceptable samples shall exhibit a 
chemical heat release rate less than $100 \mathrm{~kW}$ and a maximum visual flame height equal to or less than $1.8 \mathrm{~m}$.

\section{References}

[1] "FM Approvals Standard for Cavity Walls and Rainscreens, Class Number 4411", FM Approvals, Norwood, MA, 2016.

[2] "Invention of STYROFOAMTM"”. Dow Chemical. Retrieved January 19, 2016.

[3] "Caution - Plastics in Construction," Record, v. 77, p. 6-11, Factory Mutual Insurance Corporation, 1997.

[4] IBC 2012, Chapter 26, International Code Council, 2012.

[5] NFPA 5000, "Building Construction and Safety Code," National Fire Protection Association, Quincy, MA. 2015.

[6] ASTM D1692, "Standard Method of Test for Flammability of Plastic Sheeting and Cellular Plastics," American Society for Testing and Materials, West Conshohocken, PA. 1968.

[7] ASTM E84, "Standard Test Method for Surface Burning Characteristics of Building Materials," ASTM International, West Conshohocken, PA.

[8] Babrauskas, V., Lucas, D., Eisenberg, D., Singla, V., Dedeo, M., \& Blum, A., "Flame Retardants in Building Insulation: A Case for Re-evaluating Building Codes," Building Research and Information, 40, 738-755, 2012.

[9] FM Global, "FM Global Data Sheet 1-57: Plastics in Construction,” Norwood, MA, January 2009, Interim Revision July 2015.

[10] Choi, K.K. and Taylor, W. "Combustibility of Insulation in Cavity Walls," National Research Council Canada, Division of Building Research, 1984.

[11] NFPA 275, "Standard Method of Fire Tests for the Evaluation of Thermal Barriers," National Fire Protection Association, Quincy, MA. 2013.

[12] NFPA 286, "Standard Methods of Fire Tests for Evaluating Contribution of Wall and Ceiling Interior Finish to Room Fire Growth," National Fire Protection Association, Quincy, MA. 2015.

[13] UL 723, "Standard for Test for Surface Burning Characteristics of Building Materials", Underwriters Laboratories LLC, Northbrook, IL, 2008.

[14] NFPA 101, "Life Safety Code," National Fire Protection Association, Quincy, MA. 2015.

[15] "Fire Research on Cellular Plastics: The Final Report of the Products Research Committee," National Bureau of Standards, Washington, DC. 1980.

[16] NFPA 285, "Standard Fire Test Method for Evaluation of Fire Propagation Characteristics of Exterior Non-Load-Bearing Wall Assemblies Containing Combustible Components," National Fire Protection Association, Quincy, MA. 2012.

[17] NFPA 251, "Standard Methods of Tests of Fire Endurance of Building Construction and Materials," National Fire Protection Association, Quincy, MA. 2006.

[18] ASTM E119, "Standard Test Methods for Fire Tests of Building Construction and Materials," ASTM International, West Conshohocken, PA. 2015.

[19] ANSI/UL 263, "Standard for Fire Tests of Building Construction and Materials," American National Standards Institute/Underwriters Laboratories LLC, 2015.

[20] NFPA 268, "Standard Test Method for Determining Ignitability of Exterior Wall Assemblies Using a Radiant Heat Energy Source," National Fire Protection Association, Quincy, MA. 2012.

[21] NFPA 259, "Standard Test Method for Potential Heat of Building Materials," National Fire Protection Association, Quincy, MA. 2013.

[22] Jamison, K.L.T., Boardman, D.A., and Khan, M.M. "A New Fire Performance Test for Cavity Wall Insulation,” Proceedings of Fire \& Materials, San Francisco, CA, February 2015. 
[23] “Cavity Walls - Design Guide for Taller Cavity Walls", Masonry Advisory Council, Park Ridge, IL, 2002.

[24] ISO 9705:1993, "Fire Tests - Full-scale Room Test for Surface Products," International Organization for Standardization, Geneva, Switzerland, 1993.

[25] "FM Approvals Standard for Cleanroom Materials Flammability Test Protocol, Class Number 4910", Norwood, MA, June 2009.

[26] "FM Approvals Standard for Wafer Carriers for Use in Cleanrooms, Class Number 4911", Norwood, MA, April 2010.

[27] "Victor Torch Handles, Cutting Attachments, and Heating Nozzles Safety and Operating Instructions (Form No. 0056-0138)", Thermadyne Industries Incorporated, St. Louis, MO, May 14, 2008.

[28] "FM Global Property Loss Prevention Data Sheet 1-12, Ceilings and Concealed Spaces", FM Global, Norwood, MA, May 2008.

[29] Heskestad, G., "A Fire Products Collector for Calorimetry into the MW Range", Technical Report J.I. 0C2E1.RA, Factory Mutual Research Corporation, Norwood, MA, June 1981 (Available upon request).

[30] Khan, M.M., Jamison, K.L.T. and de Ris, J.L., "Upward Fire Growth over Thermally Thin Corrugated Paperboard," Proceedings of the $10^{\text {th }}$ International Symposium on Fire Safety Science, 2011. 